\title{
BUSINESS CYCLE MANAGEMENT AND COMPANIES PERFORMANCE: INVENTORY MANAGEMENT
}

\author{
Kaspars IESALNIEKS \\ Business Administration, Management, BA School of Business and Finance, \\ K. Valdemara Street 161, LV-1013, Riga, Latvia \\ *E-mail: kaspars.iesalnieks@gmail.com
}

\begin{abstract}
Purpose - the purpose of the research paper is to observe and analyse how major companies in the the Baltic States behave during the last business cycle in terms of inventory management in order to identify different inventory management strategies.
\end{abstract}

Research methodology - statistical analysis from year 2007 to year 2012 encompassing 1387 largest businesses in the Baltics by their operating revenue. In the research paper clustering and mainly comparison methods are applied.

Findings - research paper shows that major companies in Baltic States mainly behave cyclically and there has been little evidence of industries behaving counter-cyclically during anticipation of recession however there has been some indication of industries that increase inventories in anticipation of recovery mainly in Latvia.

Research limitations - time, geography and scope limitations in terms of financial indicator that in the future research by the author needs to be addressed in order to provide a holistic view on the issue.

Research implications - research paper demonstrates that various industries adapt different strategies during the business cycle and there are differences both on country and industry levels.

Originality - first paper that analyses in-scope major Baltic state companies behaviours during the last business cycle on both country and industry level.

Keywords: business cycle management, inventory management, companies' performance, business cycle, functional strategy.

JEL Classification: E30.

Conference topic: Contemporary Organizations Development Management.

\section{Introduction}

Global economic crisis from 2008 onwards is considered one of the worst financial crises since 1930 Great depression which had overwhelming effect on every country poor and wealthy (Ma, Yiu, \& Zhou, 2014; Bristow \& Healy, 2018; Cuadrado-Roura, Martin, \& Rodríguez-Pose, 2016; Koser, 2016; Hausman \& Johnston, 2014; Helleiner, 2014; Sherman, 1991). One of the first major signs of the Global financial crisis was on September 15th 2008 when Lehmann Brothers bankrupted (Cuadrado-Roura, Martin, \& Rodríguez-Pose, 2016). Equally US real estate bubble burst, both issues directly affected every internationally operating bank and their national economies (Tan \& Cheong, 2016; Bayer, Mangum, \& Roberts, 2016). Moreover, in 2008 Europe faced consequences of irresponsible debts carried by countries such as Greece, Spain and Italy (Zavras, Zavras, Kyriopoulos, \& Kyriopoulos, 2016). Soon Greece discovered it could not pay off their debts and the EU is still suffering because of that, as bailout amounted to 130 billion Euros. During the time period from 2008 to 2009 many of main macroeconomic indicators have decreased globally. From here arise major problems: redundancy, decrease of standard of living, bankruptcy of businesses, contraction of world trade, poverty, collapse of housing markets and et cetera (Meegan, Kennett, Jones, \& Croft, 2014; Greenglass, 2014; Ollivaud \& Turner, 2014; Magalhães, 2014; Helleiner, 2014). Thus due to major implications globally, academia has paid more attention to the business cycle management area since it's a very complex issue and there are many points of views how to look at the last business cycle specifically from 2007-2012. Meaning in this period of time there has been expansion in 2007, peak in 2008, trough in 2009 (recession for Latvia in 2009 and trough in 2010) and again expansions from 2010 onwards. For meaningful analysis just two years after 2010 are analysed since yet there has not been another peak as there is no trough however in total this time period includes all phases of the business cycle. 
Taking into account topicality aim of this research paper is to analyse how major companies in the Baltic States manage their inventories during different business cycle phases, to be more specific, during peak, recession, trough and expansion on industry level and country level (for illustration please see Figure 1) (Belongia \& Ireland, 2016; Johnson, Scholes, \& Whittington, 2007; Johnson, 2011). Research paper shows an indication and potential to discover meaningful trends in company's functional strategy regarding inventory management (Morley \& Piger, 2012; Kose \& Prasad, 2010; Stock, 1987; Češnovar, 2006; Bromiley, Navarro, \& Sottile, 2008; Bromiley, Navarro, \& Sottile, 2010; Colley, 2007). Thus if the inventory management is done in the right way and right time from an economic perspective can provide a potentially competitive advantage to the company against their peers.

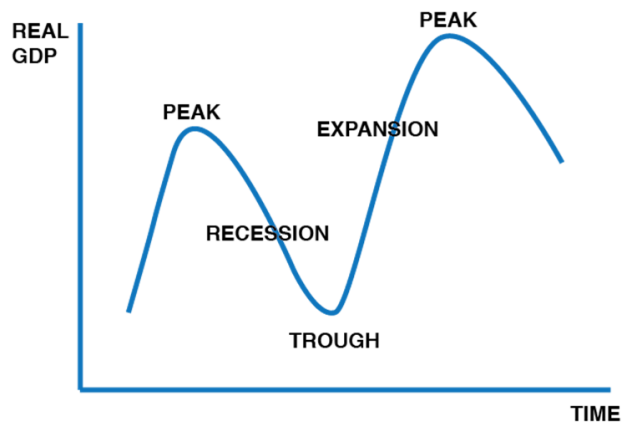

Figure 1. Business cycle phases (source: Johnson et al. (2007), Johnson (2011))

The main hypothesis of the research paper is following "Major Baltic State companies increase inventories in anticipation of recovery and cut inventories in the anticipation of recession and in other cases behave cyclically". And by performing statistical analysis of companies data aggregated on industry levels author provides an answer to the stated hypothesis as well as provides future research recommendations.

The hypothesis does originate from the literature review analysis that has been performed by Sarnovičs and Iesalnieks (2016) where current hypothesis is one of the planned series to analyse several aspects of the business cycle phase related factors by carrying out the statistical analysis.

\section{Previous research}

Based on the performed literature review by Sarnovičs and Iesalnieks (2016), that has been carried out as one of the first analysis and step within authors research topic regarding business cycle management that summarizes and categorizes current business cycle associations or factors that are used by businesses to cope with business cycles. Business cycle management (further in text - BCM) is a term that incorporates strategies of applying counter-cyclical actions and if applied in a timely way during the different business cycle phases it can improve companies performance in relative to their competitors (Dhalla, 1980 cited by Bromiley, Navarro, \& Sottile, 2010). In essence, BCM's aim is to utilize a business cycle phenomenon via counter-cyclical response to different business cycle phases (Bromiley, Navarro, \& Sottile, 2010). It must be emphasized that according to Bromiley et al. (2010) response to business cycle phases does not necessarily involve forecasting macroeconomic movements rather it embraces timely response.

The aim of this research paper is to review one of the aspects in the business cycle management that are related to inventory management to analyse how and what companies do during different business cycle phases. As several researchers have stated that one of the tools that is utilized during different business cycles to cope with the changes in inventory management in order to gain competitive advantage e.g. by reducing inventories in anticipation of a recession can reduce their inventory holding costs relative to slower acting rivals (Dhalla, 1980 cited by Bromiley, et al., 2010; Sarnovičs \& Iesalnieks, 2016). Where companies that increase inventories in anticipation of, or at the beginning of economic recovery can meet increased demand as customer purchases increase and thus gain revenue opportunities and market share relative to rivals that react less promptly (Bromiley, Navarro \& Sottile, 2008). However current research in the academia has several limitations such as sample size, no countrywide comparisons are taken into account and how different macroeconomic dynamics influence business cycle management in different industries in diverse conditions (Bromiley et al., 2008, 2010; Lorange \& Datson, 2014; Conti, Goldszmidt \& Vasconcelos, 2015).

In total whole concept about taking into account company's business strategy and especially functional strategy e.g. human resource management, quality management, creditor and debtor management, marketing mix and in particular case production and inventory management author based its model on Porter (1985) and Heerde, Gijsenberg, Dekimpe and Steenkamp (2013) also taking into GDP and industry specifics that can have an impact e.g. on market share, revenue and profit (Lamey, Deleersnyder, Dekimpe \& Steenkamp, 2007). Main focus thus is how and whether cyclical or counter-cyclical behaviour impacts results (e.g. market share, revenue or profit). Below in Figure 2 can be seen the main concept presented graphically where on the left hand-site is an environment that needs to be taken into account when reviewing both business and functional strategies and eventually current environment and different behaviours in business and functional strategies that have an impact on the results e.g. profitability. 


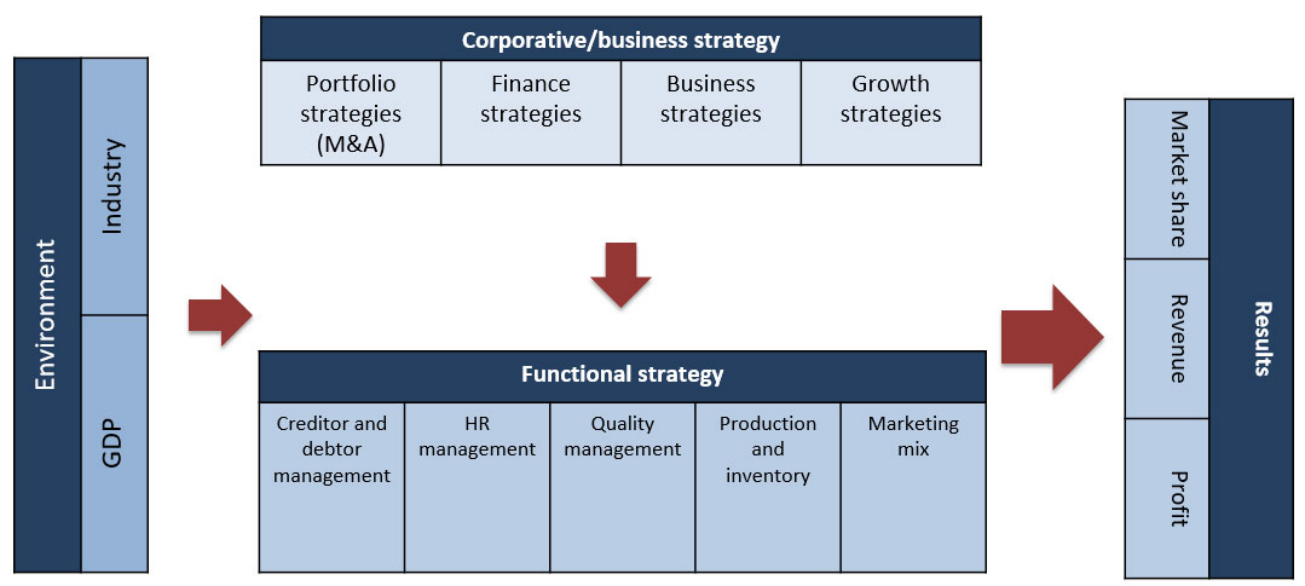

Figure 2. Main concept and research framework (source: Author's based model on Porter (1985); Heerde, Gijsenberg, Dekimpe, \& Steenkamp (2013))

Thus taking into account the model this research paper addresses identified shortcoming from the literature review in order to identify potential patterns in different business cycle phases how different industries behave in diverse countries.

\section{Research methodology}

Data is comprised from 1387 companies that are in the Baltic States from range of 17 industries that are classified taking into account NACE codes. Author has chosen 1387 companies that are the largest companies in the Baltic States by their operating revenue and includes large and medium enterprises, with more than 50 million EUR turnover for large companies and between 50 and 10 million EUR turnover for medium size enterprises respectively according to the classification of European Commission (2003). Such a choice has been made due to more availability of information for larger companies. All information was acquired via secondary database "Orbis" more detailed information can be seen below.

In terms of the time period from 2007 to 2012 it has been chosen due to the fact that this is the last full business cycle with all the phases from expansion to expansion including recession and trough as this is the latest time period where full business cycle can be observed and thus analysed how different industries and countries behave during it.

One of the main variables is states of the economy that consists of - Counter|peak, Non-Counter|peak, Counter|expansion, Non-Counter|expansion, Non-Counter|recession, Counter|recession, Non-Counter|trough and Counter|trough. Meaning that each year of companies' financial and non-financial data has been indicated in which business cycle phase it is according to GDP (gross domestic product) fluctuations. Taking into account mentioned fluctuations inventories about each of the company are analysed by following method - taking into inventories for each company depending on the results (increase or decrease of inventories) data is connected to GDP resulting in cyclical and non-cyclical behaviour summarizing results on industry and country levels.

Therefore in order to understand whether major companies in the Baltic States cut inventories during the recession and increase inventories in anticipation of a recovery main indicator for such analysis is inventory turnover indicator (Ramey \& Vine, 2004; Muller, 2011; Caro \& Gallien, 2010). The inventory turnover ratio measures the number of times inventory has been sold and replaced during the year. It is a good measure whether the inventory is obsolete if there are efficient buying practices and inventory management in general (Hançerlioğulları, Şen, \& Ağca Aktunç, 2016; Ballou, 2000; Biggart \& Gargeya, 2002; Gallino, Moreno, \& Stamatopoulos, 2016; Balcik, Bozkir, \& Kundakcioglu, 2016). Where low ratio suggests weaker sales and potentially surplus inventory where high ratio suggests stronger sales in total high ratio can suggest insufficient inventory levels (Hançerlioğulları et al., 2016; Ballou, 2000; Biggart \& Gargeya, 2002; Bromiley et al., 2010). However, in terms of this research paper analysis is carried out in a comparable manner how companies have performed in comparison to previous years thus not looking in detail whether inventory turnover was good or bad but more on a generalized level.

In order to analyse inventory turnover management data following approach was utilized:

1. Data is taken from the secondary database "Orbis" - Orbis has information on over 275 million companies across the globe. It is the resource for company data. Orbis captures and treats data from almost 160 separate providers, and hundreds of own in-house sources;

2. Data consists of 1387 companies financial and non-financial in 17 NACE categorized industries across three Baltic States - Latvia, Lithuania and Estonia; 
3. Data consists of the following companies financial indicators - operating revenue, inventory turnover and non-financial data such as NACE industry categories;

4. Data is analysed on industry level by comparing behaviour by each industry during each business cycle phase with regards to inventory turnover concluding it by whether industry encompassed companies behave countercyclically or cyclically with a proportional percentage where significant result is above $60 \%$ to conclude it as cyclical or counter-cyclical behaviour and anything below $60 \%$ is considered as balanced behaviour for each industry. Thus for instance if there are 10 companies within certain industry and more than 6 of those companies have shown countercyclical behaviour then the conclusion in the research results section will show that this particular industry behaved counter-cyclically if compared with GDP movement. Same applies the other way around for cyclical behaviour and where anything is below $60 \%$ is balanced with no particular emphasis on counter or non-counter behaviour.

\section{Research results}

While analysing data regarding the habits of inventory turnover in major companies in the Baltic States there were data reviewed and analysis for the highest point of economics, expansion of economics, recession of economics and the lowest point of economics. Data analysed differs between all three Baltic States - Estonia, Latvia and Lithuania.

When it comes to the inventory turnover habits in Estonia, Lithuania and Latvia during the highest point of economics, it was more common in the sectors to increase inventories. In Figure 3. the difference can be seen. There are sectors where there is no certain inventory turnover habit.

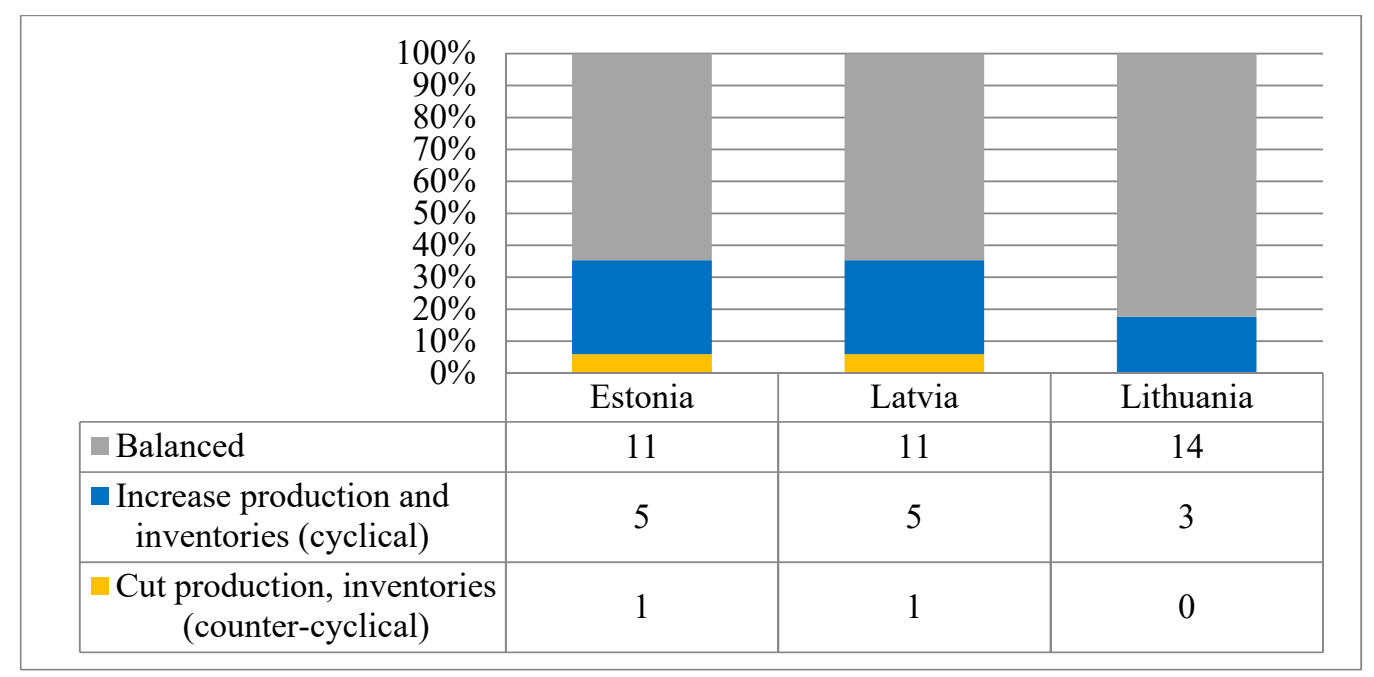

Figure 3. Inventory habits - highest point of economics

One sector, which applied counter-cyclical behavior in Estonia, was:

- Agriculture, forestry and fishing.

Whereas one sector, which applied counter-cyclical behavior in Latvia, was

- Water supply; sewerage; waste management and remediation activities.

The three sectors in Lithuania, which applied increased inventories, partly overlaps with the sectors in Estonia and Lithuania, which applied increased inventories. There were no sectors in Lithuania that applied counter-cyclical behavior. The three sectors, which applied increased inventories in Lithuania, were:

- Accommodation and food service activities;

- Agriculture, forestry and fishing;

- Mining and quarrying.

During the expansion of economics, the situation regarding applying increased inventories was common in all three Baltic States. There was one certain exception regarding cutting inventories (counter-cyclical behavior) in Estonia - Arts, entertainment and recreation. The overall situation within all three Baltic States has been visualized in Figure 4.

The seven sectors, which applied increased inventories in Estonia, were:

- Agriculture, forestry and fishing;

- Manufacturing;

- Mining and quarrying;

- Other services activities;

- Professional, scientific and technical activities;

- Water supply; sewerage; waste management and remediation activities;

- Wholesale and retail trade; repair of motor vehicles and motorcycles. 


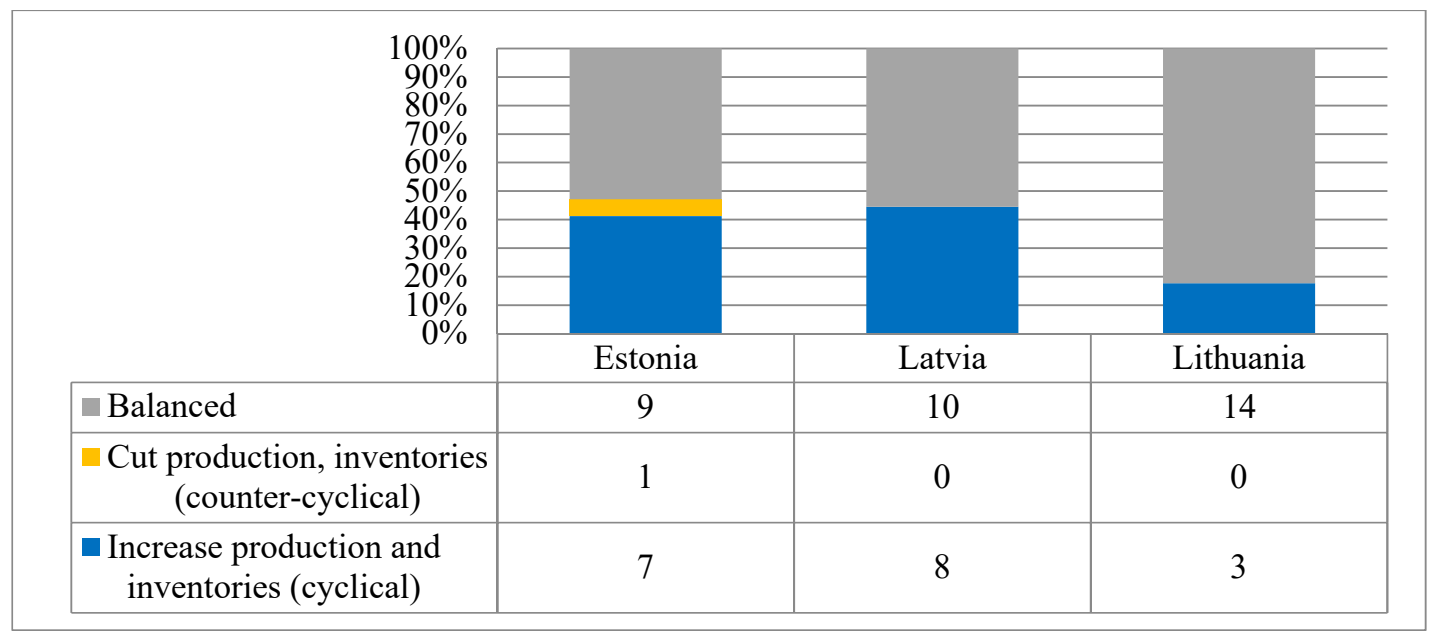

Figure 4. Expansion of economics

The eight sectors, which applied increased inventories in Latvia, were:

- Accommodation and food service activities;

- Agriculture, forestry and fishing;

- Construction;

- Manufacturing;

- Mining and quarrying;

- Public administration and defence; compulsory social security;

- Water supply; sewerage; waste management and remediation activities;

- Wholesale and retail trade; repair of motor vehicles and motorcycles.

The three sectors, which applied increased inventories in Lithuania, were:

- Agriculture, forestry and fishing;

- Information and communication;

- Wholesale and retail trade; repair of motor vehicles and motorcycles.

During the recession of economics, data were available only for one of the three Baltic States - Latvia, since Estonia and Lithuania did not have a recession and only lowest point of economy, which was followed by expansion. During the recession of economics in Latvia, it was more common to apply to cut inventories. Based on the fact, that during the highest point of economics and expansion of economics there is a common trend within all three Baltic States it can be assumed that the situation would be similar in Lithuania and Estonia. The overview of the situation in Latvia can be seen in Figure 5.

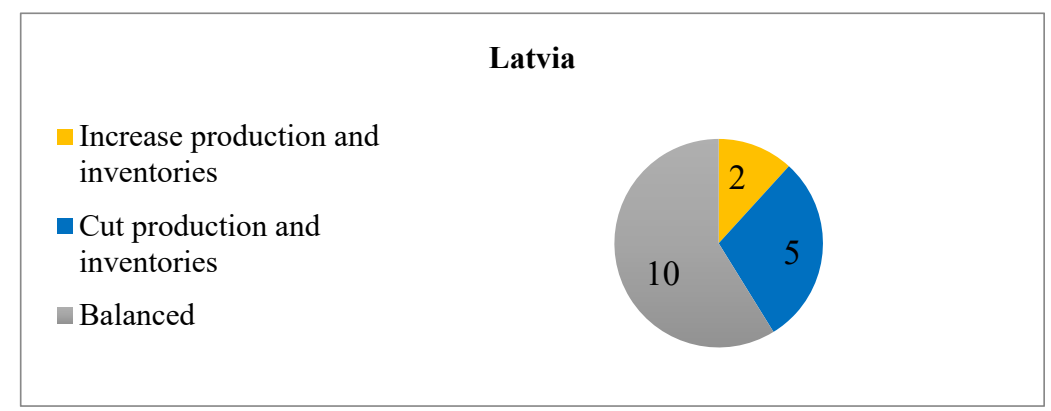

Figure 5. Inventory habits - recession of economics

The five sectors, which applied to cut inventories in Latvia, were:

- Construction;

- Human health and social work activities;

- Manufacturing;

- Public administration and defence; compulsory social security;

- Wholesale and retail trade; repair of motor vehicles and motorcycles. 
The two sectors, which applied increased inventories in Latvia (counter-cyclical behavior), were:

- Mining and quarrying;

- Water supply; sewerage; waste management and remediation activities.

During the lowest point of economics, the situation between Baltic States varies. There can be seen a trend in Estonia and Lithuania that it has been more common to apply to cut inventories, where in Latvia it was more common to apply increased inventories. The overall situation has been visualized in the Figure 6.

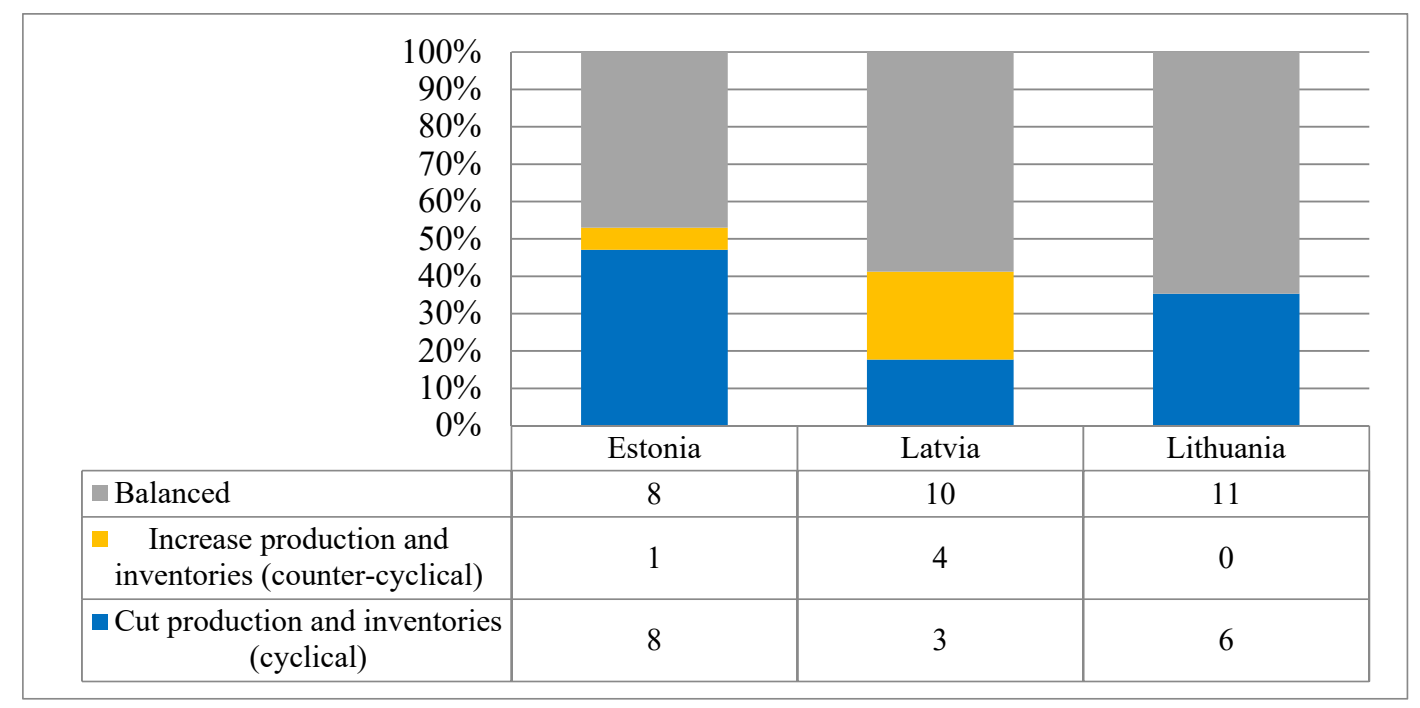

Figure 6. Inventory habits - the lowest point of economics

There was only one sector where it was more common to increase inventories (counter-cyclical behavior) during the lowest point of economics in Estonia, and it was - Water supply; sewerage; waste management and remediation activities.

The eight sectors, which applied to cut inventories in Estonia, were:

- Accommodation and food service activities;

- Agriculture, forestry and fishing;

- Arts, entertainment and recreation;

- Financial and insurance activities;

- Human health and social work activities;

- Manufacturing;

- Other services activities;

- Wholesale and retail trade; repair of motor vehicles and motorcycles.

The six sectors, which applied to cut inventories more in Lithuania, were:

- Agriculture, forestry and fishing;

- Construction;

- Electricity, gas, steam and air conditioning supply;

- Information and communication;

- Manufacturing;

- Wholesale and retail trade; repair of motor vehicles and motorcycles.

The situation in Latvia was quite different from the neighbour Baltic States. It was more common in sectors to apply increased inventories (counter-cyclical behavior). The four sectors, which applied increased inventories, were:

- Agriculture, forestry and fishing

- Human health and social work activities;

- Manufacturing;

- Mining and quarrying.

The three sectors, which applied to cut inventories in Latvia, were:

- Construction;

- Public administration and defence; compulsory social security;

- Water supply; sewerage; waste management and remediation activities. 


\section{Discussion}

As it can be seen from the research results section overall inventory habits within the Baltic States do seem similar however there are some slight differences. For instance, Lithuania has been the most cyclical country between Baltic States and have behaved very conservatively during the last business cycle through all the phases. The most apparent country, especially during trough, has been Latvia with the most counter-cyclical behavior. Estonia, as a result, is in the middle from the three countries that were included in the research scope and behavior in a very balanced manner in terms of inventory management.

The main phases to be looked as stated from the hypothesis are during peak since the aim is to understand if there have been any counter-cyclical behavior adapting to the anticipation of less demand as well as during the lowest-point of economics or trough if there has been counter-cyclical behavior anticipating before more demand. Thus if we look at the peak there are only two counter-cyclical behaviors one per Latvia and one per Estonia, however more interesting outlook can be seen during trough where in Latvia four industries and in Estonia one managed inventories as in anticipation of recovery to match increased demand.

Thus in regards to industry analysis, it can be seen that overall different industries in the Baltic States do have diverse results although trend-wise cyclical behavior is noticeable. In total utilities has shown the most sensitive aspects of the business cycle management and therefore there is a prospectus to further research to study and understand if or not there is any correlation. All in all, there are as shown by the research some industries are more or less sensitive to business cycle phases. As well as there is a trend in terms of water and related utilities business where counter-cyclical behavior can be noticed more. Therefore some industries as it can be seen are more or less prone to business cycle phases and there is an aspect to be looked at. Hence it can be seen that there are potential factors that need to be taken into account as well as their root cause that needs to be analyzed in more detail. In total as the issues can be seen in the limitations as well as conclusions that have in their account main arguments it shall be said that more qualitative research can be done to find out the root-causes for counter-cyclical behavior per each case in order to draw conclusion about potential aspects that could be generalized for any industry or may be very specific for certain industries, as a result, come up with potential holistic model within business cycle management.

\section{Limitations}

In terms of a limitation this research paper has to take into account following limitations:

- Geographical - only Baltic state (Latvia, Lithuania and Estonia) wide companies are taken into account;

- Time - very important limitation in terms of business cycle area since research paper looks at the last full business cycle that has all business cycle phases (from expansion to expansion);

- In scope are only large companies - companies that have more than 50 million EUR turnover and medium size enterprises that have a turnover between 10 million and 50 million. The limitation is due to data availability for smaller companies;

- Only one association or factor is reviewed, meaning that associations for the business cycle can be several e.g. how human resources are managed or how research and development investments vary between different business cycle phases.

\section{Conclusions}

The hypothesis stated that major companies in the Baltic States mainly behave cyclically which has been approved and there has been little evidence of companies behaving counter-cyclically during anticipation of recession however there has been some indication of companies that increase inventories in anticipation of a recovery, especially in Latvia. The data analysed shows that the hypothesis has been partially met as it has been stated. It has been more common for the Baltic States to cut inventories during the lowest point of economics and recession of economics and to apply increased inventories during the highest point of economics and expansion of economics but there is not apparent trend of higher inventories during trough. There can be identified specific exceptions from the hypothesis, which needs to be evaluated by case-by-case basis especially Latvia's situation during lowest point of the economy where counter-cyclical behavior was more apparent and somewhat closer to the stated hypothesis regarding increasing inventory in the anticipation of the recovery.

In terms of scientific benefits, it shall be emphasized that this article is one of the series from analysis of several $\mathrm{BCM}$ associations in order to come up with industry specific and generic factors or behaviors compromising them into one model that has been identified by Sarnovičs and Iesalnieks (2016) literature review as a research gap. In terms of practical benefits, there can be drawn several functional strategies for companies that can take them into account and see how to cope with different business cycle phases in a timely manner potentially providing a competitive advantage for companies for upcoming different business cycle phases. Taking into account the massive impact different business cycle phases may have on companies revenue, market share and profit such a holistic model can provide guidelines how to adapt to different business cycle phases in a timely manner and gain potentially competitive advantage 
especially nowadays taking into account dynamics of business environment. To sum up practical benefits, include need to a model to adapt to dynamic changes nowadays with different functional strategies leading to potential competitive advantage for company's higher management as an support and help during informative decision making whereas scientific benefits include answers to research gaps as there is no unified view, no comparisons on country and industry levels taking into account industry sensitive and generic factors, it is interdisciplinary research between management and economics as well as there is increased interest in academia about business cycle management since the last crisis.

Thus this is first research that analyses in-scope major Baltic state company's behaviors during the last business cycle on both country and industry levels making analytic comparisons and opening door for further research. As well as first the research identifying industry generic and sensitive business cycle management behaviors.

Consequently, author based on the performed research paper results concludes with recommendations for further research:

1. Elaborate on the reasons for different behaviours for each industry;

2. Take into account companies operating revenue for comparison objectives to understand whether non-cyclical behaviour has provided any financial gain in relative to the peers;

3. Perform more qualitative approach by carrying out interviews with company owners or using other methods to understand underlying rationale for such behaviour;

4. Research whether there are differences between large and medium sized companies behaviour;

5. Take into account more financial and non-financial indicators for a more holistic approach;

6. Review other statistical analysis methods.

\section{References}

Balcik, B., Bozkir, C. D. C., \& Kundakcioglu, O. E. (2016). A literature review on inventory management in humanitarian supply chains. Surveys in Operations Research and Management Science, 21(2), 101-116. https://doi.org/10.1016/j.sorms.2016.10.002

Ballou, R. (2000). Evaluating inventory management performance using a turnover curve. International Journal of Physical Distribution \& Logistics Management, 30(1), 72-85. https://doi.org/10.1108/09600030010307993

Bayer, P., Mangum, K., \& Roberts, J. W. (2016). Speculative fever: Investor contagion in the housing bubble (No. w22065). National Bureau of Economic Research. https://doi.org/10.3386/w22065

Belongia, M. T., \& Ireland, P. N. (2016). A classical view of the business cycle (No. 921). Boston College Department of Economics.

Biggart, T., \& Gargeya, V. (2002). Impact of JIT on inventory to sales ratios. Industrial Management \& Data Systems, 102(4), 197202. https://doi.org/10.1108/02635570210423235

Bristow, G., \& Healy, A. (Eds.). (2018). Economic crisis and the resilience of regions: a European study. Edward Elgar Publishing. https://doi.org/10.4337/9781785364006

Bromiley, P., Navarro, P., \& Sottile, P. (2010). Business cycle management and firm performance: Tying the empirical knot. Journal of Strategy and Management, 3, 50-71. https://doi.org/10.1108/17554251011019413

Bromiley, P., Navarro, P., \& Sottile, P. (2008). Strategic business cycle management and organizational performance: A great unexplored research stream. Strategic Organization, 6(2), 207-219. https://doi.org/10.1177/1476127008090011

Caro, F., \& Gallien, J. (2010). Inventory management of a fast-fashion retail network. Operations Research, 58(2), $257-273$. https://doi.org/10.1287/opre.1090.0698

Češnovar, T. (2006). The impact of strategic management on business outcomes - Empirical research. Journal for East European Management Studies, 11(3), 227-243. https://doi.org/10.5771/0949-6181-2006-3-227

Colley, J., Doyle, J., Hardie, R., Logan, G., Stettinius, W., \& Bruner, R. (2007). The strategic management process. In Principles of general management: The art and science of getting results across organizational boundaries (pp. 85-109). Yale University Press.

Conti, R., Goldszmidt, R., \& Vasconcelos, C. (2015). Strategies for superior performance in recessions: pro or counter-cyclical? Business Source Complete, 55, 273-289. https://doi.org/10.1590/S0034-759020150304

Cuadrado-Roura, J. R., Martin, R., \& Rodríguez-Pose, A. (2016). The economic crisis in Europe: Urban and regional consequences.

European Commission. (2003). Commission Recommendation of 6 May 2003 concerning the definition of micro, small and mediumsized enterprises. Retrieved from https://eur-lex.europa.eu/legal-content/EN/TXT/?uri=CELEX:32003H0361

Gallino, S., Moreno, A., \& Stamatopoulos, I. (2016). Channel integration, sales dispersion, and inventory management. Management Science, 63(9), 2813-2831. https://doi.org/10.1287/mnsc.2016.2479

Greenglass, E., Antonides, G., Christandl, F., Foster, G., Katter, J. K., Kaufman, B. E., \& Lea, S. E. (2014). The financial crisis and its effects: Perspectives from economics and psychology. Journal of Behavioral and Experimental Economics, 50, 10-12. https://doi.org/10.1016/j.socec.2014.01.004

Hançerlioğulları, G., Şen, A., \& Ağca Aktunç, E. (2016). Demand uncertainty and inventory turnover performance: An empirical analysis of the US retail industry. International Journal of Physical Distribution \& Logistics Management, 46, (6/7), 681708. https://doi.org/10.1108/IJPDLM-12-2014-0303

Hausman, A., \& Johnston, W. J. (2014). The role of innovation in driving the economy: Lessons from the global financial crisis. Journal of Business Research, 67(1), 2720-2726. https://doi.org/10.1016/j.jbusres.2013.03.021 
Heerde, H. J. V., Gijsenberg, M. J., Dekimpe, M. G., \& Steenkamp, J. B. E. (2013). Price and Advertising Effectiveness over the Business Cycle. Journal of Marketing Research, 50, 177-193. https://doi.org/10.1509/jmr.10.0414

Helleiner, E. (2014). The status quo crisis: Global financial governance after the 2008 meltdown. Oxford University Press. https://doi.org/10.1093/acprof:oso/9780199973637.001.0001

Johnson, G. (2011). Exploring strategy: Text \& cases (9 ed.). Prentice Hall, Harlow. 35.

Johnson, G., Scholes, K., \& Whittington, R. (2007). Exploring corporate strategy (8 ed.). Financial Times/ Prentice Hall, Harlow.

Kose, M., \& Prasad, E. (2010). Business cycle volatility. In Emerging markets: Resilience and growth amid Global Turmoil (pp. 6774). Brookings Institution Press.

Koser, K. (2016). The impacts of the global economic and financial crisis. In Security, insecurity and migration in Europe (pp. 8396). Routledge.

Lamey, L., Deleersnyder, B., Dekimpe, M., \& Steenkamp, J. (2007). How business cycles contribute to private-label success: Evidence from the United States and Europe. Journal of Marketing, 71(1), 1-15. https://doi.org/10.1509/jmkg.71.1.001

Lorange, P., \& Datson, E. (2014). Business cycles: looking beyond the downside for competitive advantages. Journal of Business Strategy, 35, 9-19. https://doi.org/10.1108/JBS-02-2013-0013

Ma, X., Yiu, D., 8. Zhou, N. (2014). Facing global economic crisis: Foreign sales, ownership groups, and corporate value. Journal of World Business, 49(1), 87-100. https://doi.org/10.1016/j.jwb.2013.02.002

Magalhães, P. C. (2014). Introduction-financial crisis, austerity, and electoral politics. Journal of Elections, Public Opinion \& Parties, 24(2), 125-133. https://doi.org/10.1080/17457289.2014.887090

Meegan, R., Kennett, P., Jones, G., \& Croft, J. (2014). Global economic crisis, austerity and neoliberal urban governance in England. Cambridge Journal of Regions, Economy and Society, 7(1), 137-153. https://doi.org/10.1093/cjres/rst033

Morley, J., \& Piger, J. (2012). The asymmetric business cycle. The Review of Economics and Statistics, 94(1), $208-221$. https://doi.org/10.1162/REST_a_00169

Muller, M. (2011). Inventory as money. In Essentials of inventory management (pp. 17-48). New York; Atlanta; Brussels; Chicago; Mexico City; San Francisco; Shanghai; Tokyo; Toronto; Washington, D.C.: AMACOM Division of American Management Association International.

Ollivaud, P., \& Turner, D. (2014). The effect of the global financial crisis on OECD potential output. OECD Journal: Economic Studies, 2014, 41-60.

Porter, M. E. (1985). Competitive advantage. Creating and sustaining superior performance. Free Press, New York, 557 p.

Ramey, V., \& Vine, D. (2004). Why Do real and nominal inventory-sales ratios have different trends? Journal of Money, Credit and Banking, 36(5), 959-963. https://doi.org/10.1353/mcb.2004.0075

Sarnovičs, A., \& Iesalnieks, K. (2016). Business cycle management and companies' performance: current knowledge and the way forward. Journal of Business Management, 12, 113-123.

Sherman, H. (1991). History of the business cycle. In The business cycle: Growth and crisis under capitalism (pp. 23-49). Princeton University Press.

Stock, J. (1987). Measuring business cycle time. Journal of Political Economy, 95(6), 1240-1261. https://doi.org/10.1086/261513

Tan, J., \& Cheong, S. A. (2016). The regime shift associated with the 2004-2008 US housing market bubble. PloS ONE, 11(9), e0162140. https://doi.org/10.1371/journal.pone.0162140

Van Lear, W., \& Sisk, J. (2010). Financial crisis and economic stability: A comparison between finance capitalism and money manager capitalism. Journal of Economic Issues, 44(3), 779-793. https://doi.org/10.2753/JEI0021-3624440310

Zavras, D., Zavras, A. I., Kyriopoulos, I. I., \& Kyriopoulos, J. (2016). Economic crisis, austerity and unmet healthcare needs: the case of Greece. BMC Health Services Research, 16(1), 309. https://doi.org/10.1186/s12913-016-1557-5 